\title{
Experimental Study of Combustion Oscillations in a Dual-Mode Scramjet
}

\author{
Xudong Tian, Lihong Chen *, Hongbin Gu, Can Liu, Liuwei Cheng, Xinyu Chang \\ The State Key Laboratory of High Temperature Gas Dynamics, Institute of Mechanics, C A S, No.15 \\ Beisihuanxi Road, Beijing 100190, China
}

\begin{abstract}
Characteristics of combustion oscillations were studied experimentally in a direct-connected supersonic combustion test facility with a cavity flameholder and transverse fuel injection from the wall. Static pressures were obtained by using high-frequency dynamic pressure transducers. The effects of inlet Mach number and fuel injection were examined. The frequency spectrum of wall pressures shows that combustion oscillations are different between the ramjet mode and the scramjet mode. In the ramjet mode, the high frequency combustion oscillations are on the same order of frequency as cavity oscillations. The low frequencies increase as inlet Mach number increase and fall in a range of 200-450Hz. In the scramjet mode, the high frequency combustion oscillations exist in trailing edge of the cavity, the frequencies are about $4 \mathrm{kHz}$ and the occurrence is related with transverse injection momentum ratio.
\end{abstract}

\section{Nomenclature}

$\begin{array}{ll}\mathrm{L} / \mathrm{D} & =\text { ratio of cavity length to depth } \\ \phi & =\text { equivalence ratio } \\ M a & =\text { Mach number } \\ \mathrm{H} & =\text { isolator height } \\ S P L & =\text { sound pressure level } \\ J & =\text { transverse injection momentum ratio }\left(J=\left(\rho u^{2}\right)_{j} /\left(\rho U^{2}\right)_{\infty}\right)\end{array}$

\section{Introduction}

$\mathrm{D}$ ual-mode scramjet engine is great potential propulsion system for air-breathing hypersonic aircraft. The flow entering the combustor must be kept in supersonic to avoid excessive energy loss [1]. The resident time for air in combustor is very short and on the order of $1 \mathrm{~ms}$. Therefore, fuel mixing and combustion stabilization are significant challenges for a dual-mode scramjet. Wall fuel injection and cavity flameholder are common configurations in a scramjet combustor [2]. Transverse injection of fuel from wall orifices is a simple and efficient method to enhance fuel mixing and also has a capacity for flame-holding. Cavity flameholder generates low-speed recirculation zone and provides a source of heat and radicals to stabilize combustion. However, these configurations result in flow unsteady in the combustor $[\underline{2}, \underline{3}, \underline{4}]$. The flow instabilities coupled with chemical reactions may generate combustion oscillation phenomenon [5], which is significant for the dynamic transition process, such as inlet unstart, ram-scram transition and so on. Fotia and Driscoll conducted combustion mode transition, the results show that the flame oscillations have the potential to trigger the transition event and the flame front underwent low frequency oscillations at the same frequency as the shock train under ramjet mode [] $]$.

Corresponding author. E-mail address: 1hchen@imech.ac.cn 
Ma et al. investigated the thermoacoustic instability in a scramjet and provided an acoustic-convective feedback loop between the fuel injector and the flame zone to explore the mechanisms of thermoacoustic flow instabilities [7]. The research by Lin et al. shows that the oscillation frequencies fall in a range of $100-400 \mathrm{~Hz}$ inside an ethylene-fueled scramjet combustor []]. Wang et al. studied pressure and flame oscillations in a scramjet combustor experimentally [9]. High-speed imaging results show intense flame oscillations exist and no dominant frequency less than $2 \mathrm{kHz}$ is observed. Extensive efforts have been applied to study the problem of combustion oscillations, but the mechanism is still unclear and the influencing factors are still inexplicit.

The purpose of this paper is to investigate the combustion oscillations both in the ramjet mode and the scramjet mode, and also examine the influences of the inlet Mach number and transverse injection upon the combustion oscillations in the combustor of a dual-mode scramjet engine.

\section{Experiment setup}

Experiments were performed on the direct-connected supersonic combustion facility in Institute of Mechanics, Chinese Academy of Sciences, as shown schematically in Fig. 1. Hydrogen fueled heater was used to heat the air up to $2000 \mathrm{~K}$ and additional oxygen was added to maintain a $21 \% \mathrm{O}_{2}$ mole fraction in the vitiated air. The two dimensional nozzle can be changed to implement different Mach number of 1.8, 2.2, 2.5 and 3.0, respectively, to simulate flight Mach $4-6$ conditions. The followed is the constant area isolator with the length of $395 \mathrm{~mm}$ and the height of $40 \mathrm{~mm}$. The combustor consists of two diverging sections and the divergence angles are $1.5^{\circ}$ and $2^{\circ}$, respectively. The width of the test section is $85 \mathrm{~mm}$.

A recessed cavity flameholder is located at the divergent top wall and spans the test section, as shown in Fig. 2. The depth of the cavity is $18 \mathrm{~mm}$, length to depth ratio (L/D) is 5 and the aft angle is $45^{\circ}$. Ethylene was used as the main fuel and injected from Jet 1 and Jet2, which are $10 \mathrm{~mm}$ and $60 \mathrm{~mm}$ upstream of the cavity leading edge, respectively. Injection port diameter was $0.8 \mathrm{~mm}$ or $1 \mathrm{~mm}$ at Jet 1 injector depending on the desired fuel injection momentum ratio. Jet 2 injector with $1 \mathrm{~mm}$ diameter was open when the need of fuel flux increased. Pilot fuel was injected into the cavity and closed with spark plug after ethylene fuel was ignited.

The wall static pressure was recorded by high-frequency pressure transducers at $50 \mathrm{kHz}$ at thirteen locations $(\mathrm{K} 1-\mathrm{K} 13)$ in the isolator and combustor around the cavity, shown in Fig. 1. The high-frequency transducers connect the inner wall by 0.8 diameter and $2 \mathrm{~mm}$ depth holes to protect from thermal loads. Stable wall static pressures along the facility were captured by an electronic pressure scanning system. Schlieren system is used to visualize the shock waves in the isolator. Schlieren images were captured by a CDD camera with 512 x 128 pixel resolution. The exposure time was $1 \mu \mathrm{s}$ and the frame rate was 10000 fps. The chemiluminescence of $\mathrm{CH}^{*}$ is used to mark the flame zones at the cavity. The luminosity from $\mathrm{CH}^{*}$ was imaged by a common CCD camera with $\pm 10 \mathrm{~nm}$ bandwidth interference filters centered at $430 \mathrm{~nm}$ and the exposure time was $1 / 2000 \mathrm{~s}$.

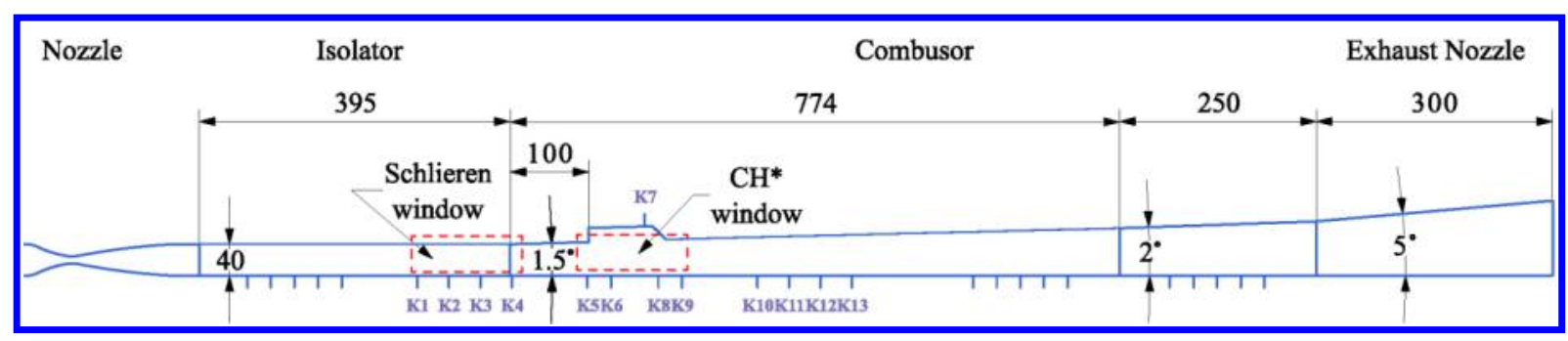

Fig. 1 Schematic of combustor and distribution of transducers 


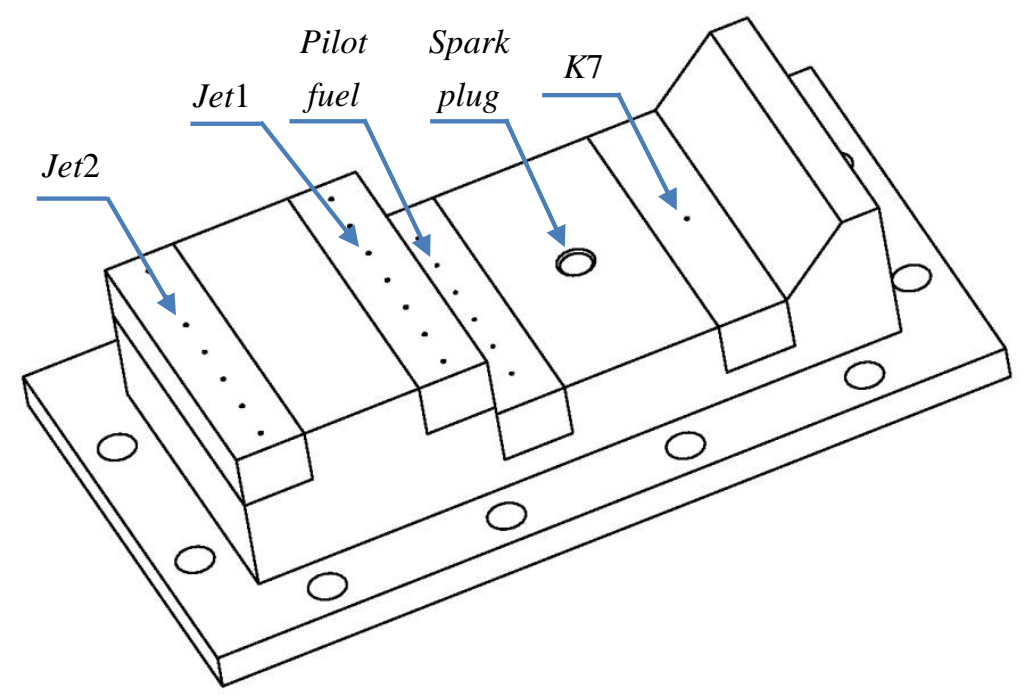

Fig. 2 Integrated 3D schematic of cavity flameholder and fuel injection blocks

\section{Result and discussion}

\section{A. Combustion oscillations in the ramjet mode}

There are two modes of combustion in the combustor. In the ramjet mode, the pressure rise due to combustion propagated upstream and the strong shock train held in the isolator, then the Mach number was less than 1 in the main reaction zone. However, in the scramjet mode, the pressure didn't propagate upstream, the shock train went through the whole zone and the main flow remained supersonic.

Combustion characteristics in the ramjet mode were achieved for the conditions listed in Table 1. The pressure history at various positions for Case A1 was shown in Fig. 3, $\mathrm{x}=0$ corresponding to the entrance of the isolator. The inlet flow was in a desired steady state without fuel injection during $\mathrm{t}=5-5.5 \mathrm{~s}$. When $\mathrm{t}=7.6 \mathrm{~s}$, main fuel was transverse injected from Jet 1 and Jet 2 orifices and the combustor was in the ramjet mode, which continued until $t=8.3 \mathrm{~s}$. During the ramjet mode, the flow field was quite unsteady both in the isolator and the combustor. Wall static pressures fluctuated seriously around the cavity while the amplitudes of pressure oscillations were larger and close to $200 \mathrm{kPa}$ at $\mathrm{K} 1-\mathrm{K} 4$ in the isolator, as shown in Fig. 3.

Table 1 Experimental conditions for Case A

\begin{tabular}{ccccc}
\hline Case & Ma & $\mathrm{P}_{0}(\mathrm{MPa})$ & $\mathrm{T}_{0}(\mathrm{~K})$ & $\phi$ \\
\hline $\mathrm{A} 1$ & 2.2 & 1.13 & 1175 & 0.34 \\
$\mathrm{~A} 2$ & 2.2 & 1.14 & 1179 & 0.22 \\
$\mathrm{~A} 3$ & 2.2 & 1.10 & 1153 & 0.29 \\
$\mathrm{~A} 4$ & 2.5 & 1.59 & 1434 & 0.32 \\
\hline
\end{tabular}

Fig. 4 shows that wall pressure begins to rise at $\mathrm{x} / \mathrm{H}=-8.6$ (from cavity leading edge, same below), and comes to the peak near the cavity, then drops rapidly. The pressure standard deviations indicate that the shock train was unsteady and caused violent pressure fluctuation in the isolator. Shock train moved upstream and downstream in the isolator, observed through continuous schlieren images. Fotia and Driscoll's research shows that the unsteady behavior of shock train is related with the fluctuations in main flame front $[\underline{6}, \underline{10}]$.

Fig. 5 show the FFT results of pressures at $\mathrm{K} 3(\mathrm{x} / \mathrm{H}=-3.45)$ and $\mathrm{K} 6(\mathrm{x} / \mathrm{H}=0.7)$, located at the isolator and the cavity leading edge, respectively. The ordinate axis represents sound pressure level (SPL). The low dominant frequency of pressure oscillations at $\mathrm{K} 6$ is about $330 \mathrm{~Hz}$ shown in Fig. 5b), which is similar to the flow 
oscillation frequency about $350 \mathrm{~Hz}$ reported by Ma et al. for a scramjet engine with ethylene fueled [7]. The sound pressure level of low frequency oscillation is as high as $170 \mathrm{~dB}$. In addition, the flame front was unsteady shown by continuous $\mathrm{CH}^{*}$ chemiluminescence images. The explanation for the low frequency oscillations is that the flame front is pushed upstream by the rise of back pressure due to heat release and then transported downstream by the high-speed incoming flow as back pressure not high enough to maintain the forward propagation or anchoring. Their competition results in low frequency combustion oscillations.

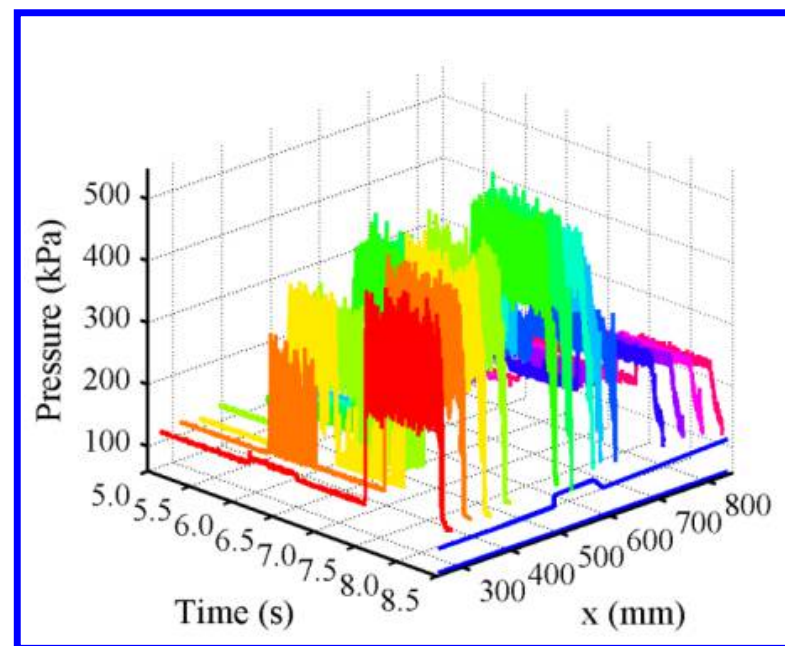

Fig. 3 High frequency pressure measurements for Case A1

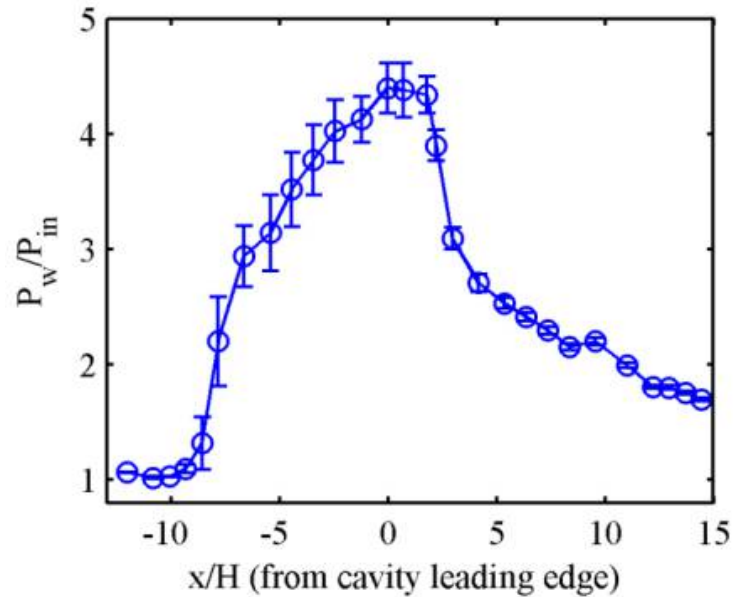

Fig. 4 Wall static pressure average and standard deviation (half of the bars) for Case A1

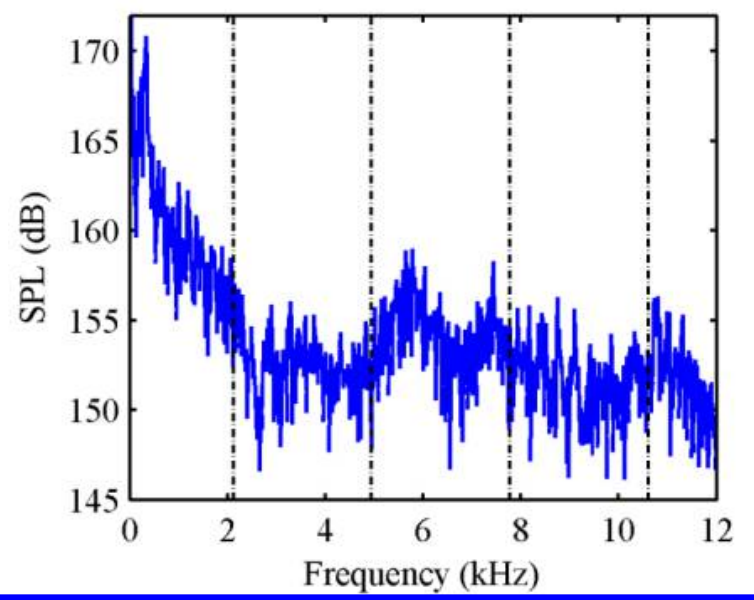

b) $\mathrm{K6}(\mathrm{x} / \mathrm{H}=\mathbf{0 . 7})$

a) $\mathrm{K3}(\mathrm{x} / \mathrm{H}=-\mathbf{3 . 4 5})$

Fig. 5 Frequency spectra of pressure at $\mathrm{K3}$ and $\mathrm{K} 6$ for Case A1, dash lines indicate the cavity oscillation frequencies predicted by Rossiter's semi-empirical formula

Substantial pressure fluctuations were caused by the unsteady of shock train in the isolator. The spectrum of pressure at K3 contains three dominant frequencies shown in Fig. 5a, which are $317 \mathrm{~Hz}, 684 \mathrm{~Hz}$ and $1.27 \mathrm{kHz}$, respectively. The lowest is close to the low dominant frequency of combustion oscillations. This is consistent with Fotia and Driscoll's results [] $]$, but the frequency value is much higher.

Three high spectral components are observed in Fig. 5b and their sound pressure levels are lower than the sound pressure levels of the low main frequency $10 \mathrm{~dB}$. These high frequencies are $5.64 \mathrm{kHz}, 7.43 \mathrm{kHz}$ and $10.73 \mathrm{kHz}$, respectively. The cavity oscillation frequency of $m$ th mode proposed by Rossiter [3] is given by 


$$
f_{m}=\frac{m-\alpha}{M_{\infty}+1 / k} \cdot \frac{U_{\infty}}{L}
$$

where $L$ is the cavity length, $U_{\infty}$ and $M_{\infty}$ are the free-stream velocity and Mach number, $\alpha$ and $k$ are empirical constants. These high frequencies of combustion oscillations approach the second, third and fourth mode of cavity oscillations, respectively. It indicates that thermoacoustic flow instabilities exist in the combustion zone and the oscillation frequencies are affected by the cavity structure and changed by combustion a little.

The influences of fuel equivalent ratio and inlet Mach number are enormous for combustion regime. Fig. 6 shows the differences of spectrums of pressure at $\mathrm{K} 6$ for different equivalent ratios. The sound pressure levels of high frequency oscillations at $\phi=0.22$ is lower than those at $\phi=0.34$ and the frequencies shift to low as the fuel equivalent ratio decreases. Significant variations of spectrum of pressure occur at combustion zone as the inlet Mach number increases, as shown in Fig. 7. The low base frequency is $244 \mathrm{~Hz}$ at $\mathrm{Ma}=2.2$ and up to $415 \mathrm{~Hz}$ at $\mathrm{Ma}=2.5$. When the inlet Mach number increases, the competition between the back pressure in combustor and incoming flow intensifies, so the low dominant frequency increases. At $\mathrm{Ma}=2.5$, the spectra components of high frequency oscillations are not observed in Fig. 7. The variations of fuel equivalent ratio and inlet Mach number change the intension and distribution of heat release, which indicates that heat release effect the occurrence of thermoacoustic oscillations.

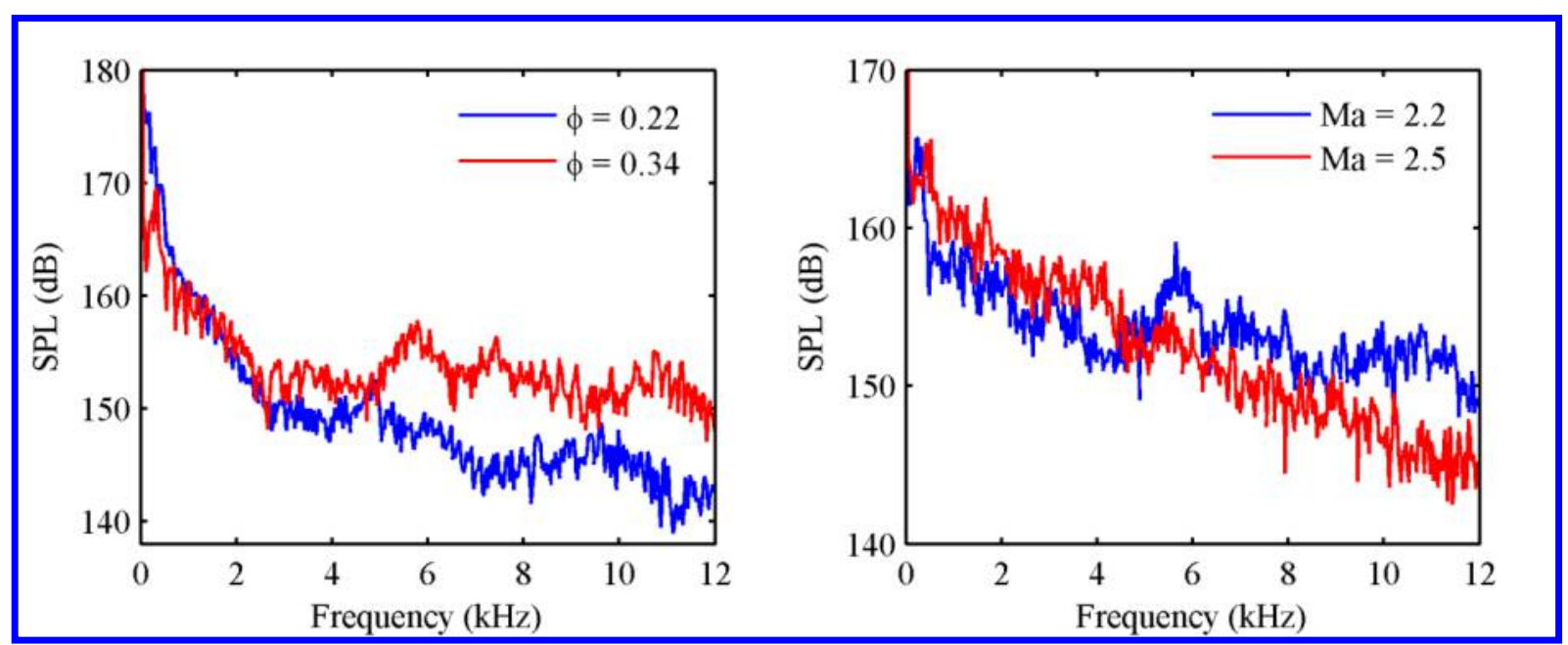

Fig. 6 Frequency spectra of pressure at $\mathrm{K6}(\mathrm{x} / \mathrm{H}$ = 0.7) for Case A1 and Case A2

Fig. 7 Frequency spectra of pressure at $\mathrm{K6}(\mathrm{x} / \mathrm{H}$ = 0.7) for Case A3 and Case A4

\section{B. Combustion oscillations in the scramjet mode}

In the scramjet mode, the main flow maintains supersonic in the combustor and no thermal choke exists. The combustion regime is quite different from that in the ramjet mode. The combustion oscillation characteristics were investigated in Case B, which conditions are listed in Table 2.

Table 2 Experimental conditions for Case B

\begin{tabular}{cccccc}
\hline Case & $\mathrm{Ma}$ & $\mathrm{P}_{0}(\mathrm{MPa})$ & $\mathrm{T}_{0}(\mathrm{~K})$ & $\phi$ & $J$ \\
\hline $\mathrm{B} 1$ & 2.5 & 1.59 & 1422 & 0.14 & 1.57 \\
$\mathrm{~B} 2$ & 2.2 & 1.10 & 1192 & 0.12 & 1.58 \\
$\mathrm{~B} 3$ & 2.5 & 1.54 & 1387 & 0.12 & 1.47 \\
$\mathrm{~B} 4$ & 3.0 & 2.47 & 1522 & 0.12 & 1.25 \\
$\mathrm{~B} 5$ & 2.5 & 1.56 & 1469 & 0.16 & 1.70 \\
$\mathrm{~B} 6$ & 2.5 & 1.59 & 1434 & 0.17 & 1.84 \\
\hline
\end{tabular}


Fig. 8 shows the histories of high frequency pressure at various positions for Case B1. By $\mathrm{t}=7.6 \mathrm{~s}$, pilot hydrogen was turned off and the combustor was in the scramjet mode with ethylene fuel from Jet 1 site. Then the self-sustained combustion maintained until $\mathrm{t}=8.3 \mathrm{~s}$. Large pressure fluctuations occurred around the cavity trailing edge and downstream while the disturbances weren't propagated upstream to the isolator.

The FFT applications were employed for the high frequency pressures and the results show that high dominant frequency oscillations only existed in the vicinity of the cavity trailing edge. Fig. 9 shows the frequency spectrum of pressure at $\mathrm{K} 9(\mathrm{x} / \mathrm{H}=2.95)$. The low dominant frequency is unclear and the high dominant frequency is $3.86 \mathrm{kHz}$. Additionally, the high dominant frequency is between the first and second mode of cavity oscillations, as predicted by Rossiter semi-empirical formula, of $2.34 \mathrm{kHz}$ and $5.46 \mathrm{kHz}$, respectively. At the rear of the cavity, the instabilities of the shear layer spanning the cavity are coupled with chemical reactions and affected by the cavity structure. Their interactions may be the main reasons for the high frequency oscillations.

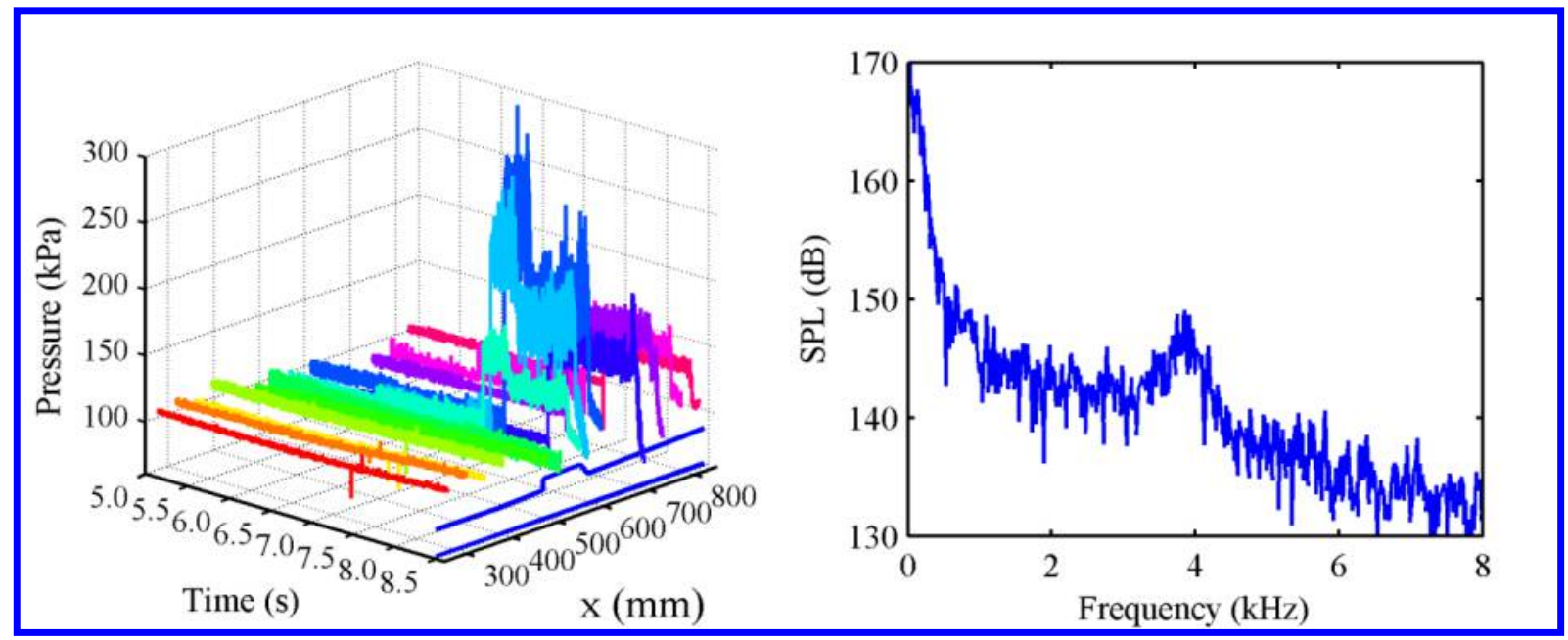

Fig. 8 High frequency pressure measurements for

Fig. 9 Frequency spectrum of pressure at $\mathrm{K9}(\mathrm{x} / \mathrm{H}$ Case B1 =2.95) for Case $B 1$

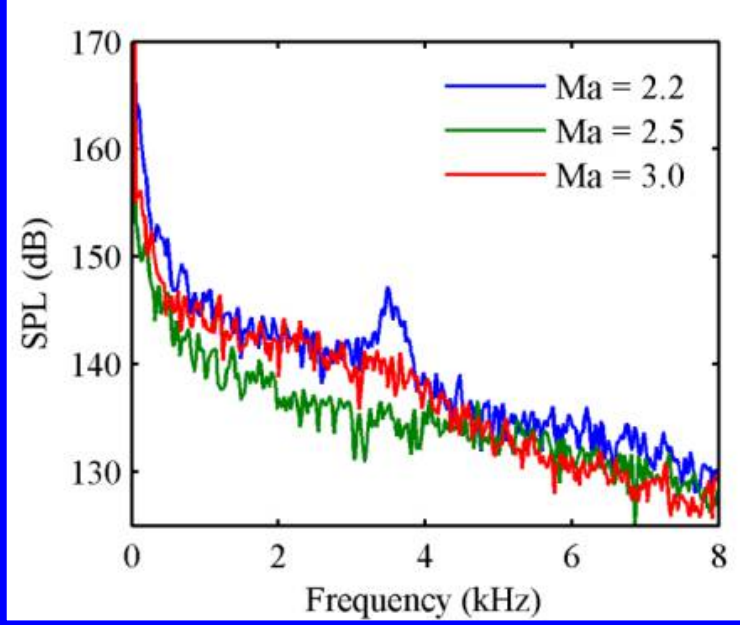

Fig. 10 Frequency spectra of pressure at $\mathrm{K} 9(\mathrm{x} / \mathrm{H}$ =2.95) for Case B2, Case B3 and Case B4

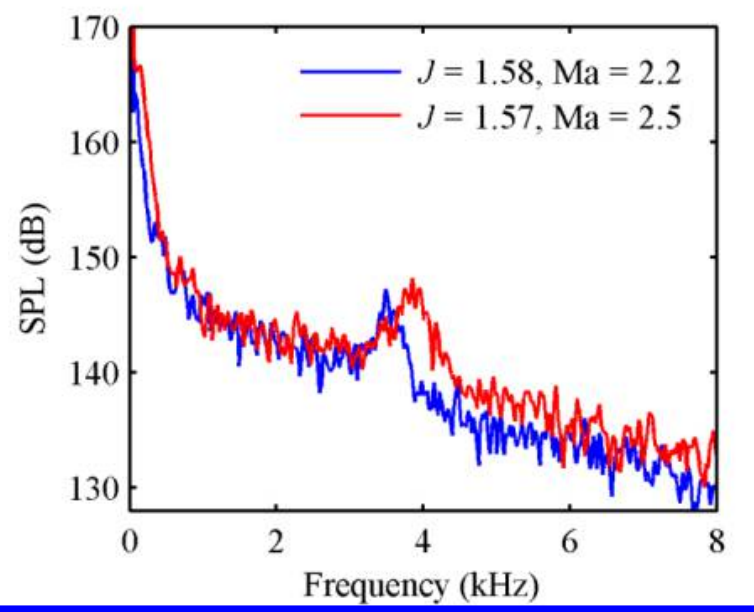

Fig. 11 Frequency spectra of pressure at $\mathrm{K9}(\mathrm{x} / \mathrm{H}$ =2.95) for Case B1 and Case B2

The influences of inlet Mach number and transverse injection were also examined in the scramjet mode. Fig.10 shows the frequency spectra of pressure at K9 with different inlet Mach number and constant fuel equivalence ratio of 0.12 . High dominant frequency is observed at $\mathrm{Ma}=2.2$ and is inconspicuous as inlet Mach 
number increase. Fig. 11 shows that the frequency spectra of pressure at K9 are similar for the same injection momentum ratio with different inlet Mach number and their high dominant frequencies are about $4 \mathrm{kHz}$. It suggests that transverse injection momentum ratio may be the main factor in high frequency oscillations.

Fig. 12 shows the frequency spectra of pressure at the trailing edge of the cavity with various momentum ratios. The high dominent frequency is apparent as momentum ratio is in a certain range. Paramoschou and Hubbard's research indicates that penetration height of jet normal to a supersonic cross flow depends strongly on momentum ratio $J$ [11]. When $J$ is in a certain range, normal fuel jet changes direction after penetrates a certain height and is transported downsteam, the unsteady vortical structures interact with the shear layer above the cavity, which intensifies the instabilities of the shear layer. Fig. 13 are $\mathrm{CH}^{*}$ chemiluminescence images for different momentum ratio. The angle of flame front with respect to crossflow is increasing in the tail of the cavity at $J=1.70$ and decreasing in the other two cases. It indicates a complicated coupling among unsteady vortical stuctures caused by fuel injection, instabilities of the shear layer, cavity structure and combustion leads the high frequency oscillations.

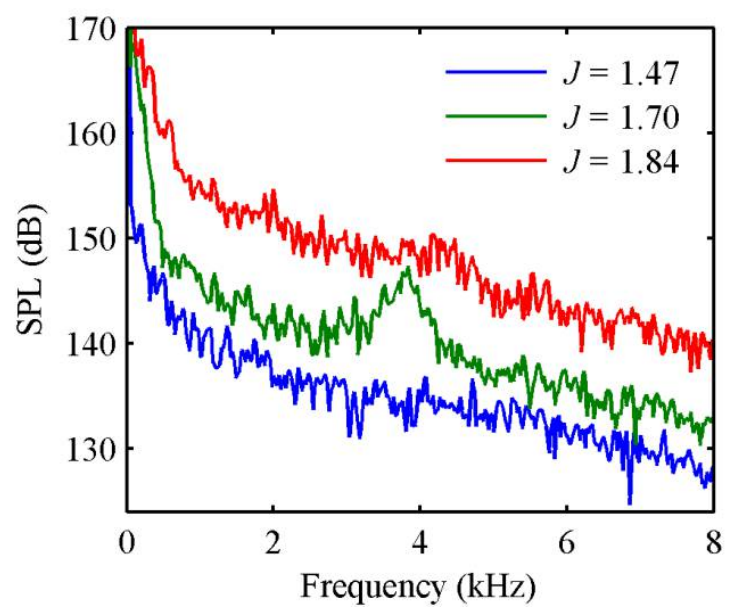

Fig. 12 Frequency spectra of pressure at $\mathrm{K9}(\mathrm{x} / \mathrm{H}$ =2.95) for Case B3, Case B5 and Case B6. a)

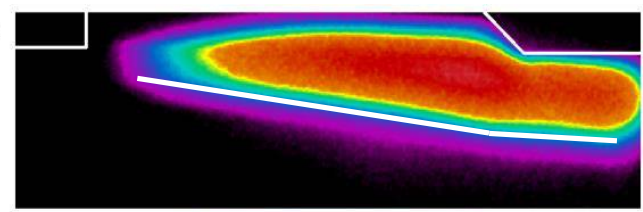

b)

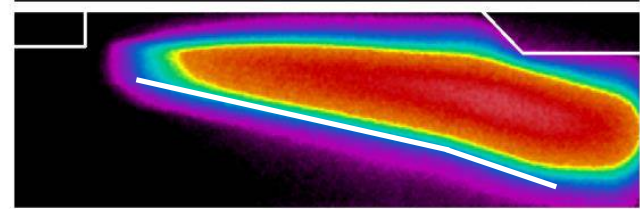

c)

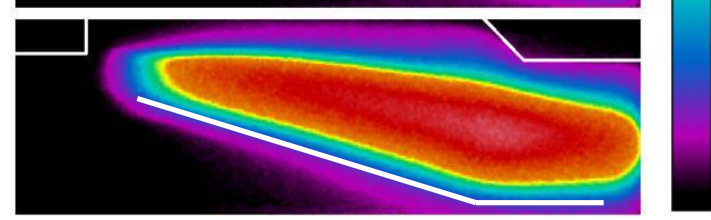

Fig. $13 \mathrm{CH}^{*}$ chemiluminescence images: a) $J=1.47$, b) $J=1.70$, c) $J=1.84$

\section{Conclusions}

In this paper, combustion oscillations were studied both in the ramjet /scramjet mode with ethylene fuel and the influences of the inlet Mach and transverse injection were also investigated.

In the ramjet mode, there are low dominant frequency oscillation with high sound pressure level and high frequency oscillations with low sound pressure level in the combustion zone simultaneously. The low dominant frequency oscillation is related to the unsteady of flame front and the oscillation frequency increases as inlet Mach number increases. The high frequency oscillations are affected by the interactions among the shear layer, cavity oscillations and combustion and are same level of frequency as cavity self-sustaining oscillations.

In the scramjet mode, high dominant frequency oscillations exist in the cavity trailing edge and the frequency is about $4 \mathrm{kHz}$. The occurrence of high frequency oscillations is influenced by the transverse injection momentum ratio.

\section{References}

Curran, E. T., W. H. Heiser, and D. T. Pratt. "Fluid phenomena in scramjet combustion systems." Annual Review of Fluid Mechanics 28.1 (1996): 323-360. 
${ }^{2}$ Ben-Yakar, Adela, and Ronald K. Hanson. "Cavity flame-holders for ignition and flame stabilization in scramjets: an overview." Journal of Propulsion and Power 17.4 (2001): 869-877.

${ }^{3}$ Rossiter, J. E. "Wind tunnel experiments on the flow over rectangular cavities at subsonic and transonic speeds." Ministry of Aviation; Royal Aircraft Establishment; RAE Farnborough, 1964.

4 Ben-Yakar, Adela. "Experimental investigation of mixing and ignition of transverse jets in supersonic crossflows." Diss. stanford university, 2000.

${ }^{5}$ Choi, Jeong-Yeol, et al. "DES combustion modeling of a scramjet combustor." AIAA Paper 5097 (2006): 2006.

${ }^{6}$ Fotia, Matthew L., and James F. Driscoll. "Ram-scram transition and flame/shock-train interactions in a model scramjet experiment." Journal of Propulsion and Power 29.1 (2012): 261-273.

${ }^{7}$ Ma, F. H., et al. "Thermoacoustic flow instability in a scramjet combustor." AIAA paper 3824 (2005): 2005.

${ }^{8}$ Lin, Kuo-Cheng, et al. "Acoustic characterization of an ethylene-fueled scramjet combustor with a cavity flameholder." Journal of Propulsion and Power 26.6 (2010): 1161-1170.

${ }^{9}$ Wang, Hongbo, Zhenguo Wang, and Mingbo Sun. "Experimental study of oscillations in a scramjet combustor with cavity flameholders." Experimental Thermal and Fluid Science 45 (2013): 259-263.

${ }^{10}$ Fotia, Matthew L., and James F. Driscoll. "Isolator-combustor interactions in a direct-connect ramjet-scramjet experiment." Journal of Propulsion and Power 28.1 (2012): 83-95.

${ }^{11}$ Papamoschou, Dv, and D. G. Hubbard. "Visual observations of supersonic transverse jets." Experiments in Fluids 14.6 (1993): 468-476. 